\title{
Epidemiologically Relevant Container Types, Indices of Abundance and Risk Conditions for Aedes aegypti in Salto (Uruguay), a City under Threat of Dengue Disease
}

\author{
César Basso ${ }^{{ }^{*}}$, Elsa García da Rosa ${ }^{2}$, Rosario Lairihoy ${ }^{2}$, Cristina González ${ }^{3}$, Walter Norbis ${ }^{4}$, Ingrid Roche ${ }^{5}$, Ruben M. Caffera ${ }^{6}$ and Ricardo da Rosa ${ }^{7}$ \\ ${ }^{1}$ Unidad de Entomología, Facultad de Agronomía, Universidad de la República, Montevideo, Uruguay \\ ${ }^{2}$ Departamento de Parasitología Veterinaria, Facultad de Veterinaria, Universidad de la República, Salto, Uruguay \\ ${ }^{3}$ Dirección Departamental de Salud, Ministerio de Salud Pública, Salto, Uruguay \\ ${ }^{4}$ Departamento de Biología Animal, Facultad de Ciencias, Universidad de la República, Montevideo, Uruguay \\ 5Instituto de Teoría de la Arquitectura y Urbanismo, Facultad de Arquitectura, Universidad de la República, Montevideo, Uruguay \\ ${ }^{6}$ Unidad de Sistemas Ambientales, Facultad de Agronomía, Universidad de la República, Montevideo, Uruguay \\ ${ }^{7}$ Dirección Departamental de Salud, Ministerio de Salud Pública, Salto, Uruguay
}

*Corresponding author: César Basso, Facultad de Agronomía, Av. Garzón 780, 12900 Montevideo, Uruguay, Tel: +598 2359 7191; E-mail: cbasso@movinet.com.uy

Received date: November 12, 2015; Accepted date: December 15, 2015; Published date: December 25, 2015

Copyright: ( 2015 Basso C, et al. This is an open-access article distributed under the terms of the Creative Commons Attribution License, which permits unrestricted use, distribution, and reproduction in any medium, provided the original author and source are credited.

\begin{abstract}
Objective: A study was conducted in Salto (Uruguay), a city recently invaded by Aedes aegypti (Diptera, Culicidae), in order to identify mosquito-producing containers, the relationship between different Aedes aegypti population indices and environmental risk conditions for the dengue vector. Due to uruguayan climatic characteristics, the vector population decreases abruptly during the winter and regrows when temperature rises, resulting in a particular population dynamic that differs from that of tropical regions.
\end{abstract}

Methods: 20 clusters randomly selected (100 household each) were visited twice and water filled containers and immature mosquitoes were quantified. Pupae per person (PPI), pupae per hectare (PPH) and Stegomyia indices were calculated. The number of mosquitoes in each container type was analyzed, and their spatial location was described.

Results: The study was able to detect important epidemiological containers (containers not in use and tanks). While PPI, PPH and Stegomyia indices for the different clusters were correlated, the Stegomyia indices increased significantly between the first and second sampling. Clusters with abundant vegetation, or located on lower ground showed the highest PPI values.

Conclusion: Due to its proximity to areas where dengue fever is endemic, Salto becomes valuable for case studies relevant to other areas in the world that could be invaded by this vector.

\section{Introduction}

The world health organization (WHO) has estimated that 50-100 million of dengue virus infections occur annually while a recent study calculated that the true figure may be closer to 400 million [1-3]. Dengue is endemic throughout the tropics and it has been confirmed in 128 countries worldwide [4,5]. The geographic extension of dengue is essentially determined by the distribution of its primary vector, the mosquito Aedes aegypti (L.) (Diptera, Culicidae). This species is commonly found in high numbers in urban areas, living close to human dwellings, where females usually breed in man-made containers [6].

Human migration probably includes infected people and international travel constantly introduces new vectors to new geographic areas [7]. It has also been suggested that temperature increases and global climatic change could lead to the spread of mosquito vectors into new areas, to the lengthening of the transmission season in already endemic regions and also the increase of the effectiveness of the mosquito as a vector [8-10]. It can be mentioned as examples that three autochthonous cases of dengue were reported in Europe in 2010 [11,12], and 27 and 63 autochthonous cases were documented in Florida (United States of America) in 2009 and 2010, respectively, for the first time in over 50 year (Centers for disease control [CDC] 2010, Graham, et al. 2011), underlining the fact that the introduction of dengue in not-endemic areas is a real threat.

In new territories, where the disease has spread recently, it is necessary to develop approaches and measures aimed to surveillance and prevention, in addition to keep vector populations low, to detect new outbreaks of the disease on time-improving also the ability to distinguish, in an early phase, dengue from other febrile illnesses, and to develop better response mechanisms to minimize the consequences of such outbreaks (see rationale and hypotheses of three european dengue research consortia for a complete development of the subject [13]). The further spread of the disease into previously uninfected areas must be avoided.

In South America, Aedes aegypti covers a geographical area reaching to the province of Neuquén (Argentina) (sporadic 
Citation: Basso C,Garcia da Rosa E, Lairihoy R, Gonzalez C, Norbis W, et al. (2016) Epidemiologically Relevant Container Types, Indices of Abundance and Risk Conditions for Aedes aegypti in Salto (Uruguay), a City under Threat of Dengue Disease. J Infect Dis Pathol 1 : 103.

occurrence). This is the southernmost distribution area found in the continent $[14,15]$. Since 1997, Uruguay has been-once again after almost 40 years-part of the Aedes aegypti distribution [16]. This country is located very close to the southernmost geographic limit of the distribution of the dengue fever vector in the continent. Despite the efforts of the uruguayan authorities (Ministry of Public Health-MPH, Municipalities) which involve public education, container disposal, monitoring with overtops and use of insecticides [17], the vector's distribution has steadily increased and now occupies much of the Uruguayan territory [18]. Even though the reported dengue cases in Uruguay were all imported, the country is surrounded by dengue endemic areas (Argentina and Brazil) [19]. As a consequence of this fact, Uruguay must be considered a threatened area [20].

Because of its geographic location, Uruguay has long periods during which temperatures fall below oviposition and activity thresholds of Aedes aegypti, and into the lethal range for the vector, as suggested by Christophers [21] and Focks, et al. [22,23]. The vector population regrows when temperature rises, resulting in a particular population dynamic that differs from that of tropical regions where the disease is endemic [24].

Dengue surveillance and dengue case investigation studies in the world include the use of traditional mosquito indices (the Stegomyia indices: the Container Index-CI: percentage of water-holding containers with immature stages of Aedes aegypti, the House IndexHI: percentage of inspected houses with immature stages of Aedes aegypti and the Breteau Index-BI: number of containers with immature stages of Aedes aegyptil 100 houses) that take into account the density of Aedes aegypti. However, these entomological indices alone do not provide an accurate measure of the threshold required for dengue transmission and dengue control. The development of the key premises and key containers concepts demonstrated that some premises and containers produce a larger number of immature and collectively produce larger numbers of Aedes aegypti adults than other premises and containers [25]. Chadee [26] merged the concept of key premises and key containers with the pupal indices [27] which quantified for the first time the adult productivity of 17 different container types from key premises in Trinidad. The combined concepts revealed that container productivity and the risk of disease transmission based on the number of people living in each house (the number of pupae per person index-PPI) or the number of pupae per hectare index (PHI) may serve as an improved indicator in ecological settings where dengue is an important public-health problem. Those indicators could then be used for the development of more cost effective, targeted approaches to vector control and dengue suppression programs [28-33].

In Uruguay, a study performed in the peridomestic areas of 312 households visited three times in the city of Salto in 2008 could not find significant differences in the number of the different types of containers with mosquitoes or in the number of mosquitoes in each [20]. This would have been a useful tool for prioritizing vector-control interventions. In this new study in the city of Salto, a change in the methodology previously applied (twenty clusters selected randomly in the city and an increase of households visited) aimed to identify the important Aedes aegypti-producing containers (their importance being a function of a container's abundance and its productivity), to relate the values of pupal indices with environmental conditions and to analyze the relationship between Stegomyia and pupae per person indices and by survey dates. Finally, we discussed the implications of our findings involving estimating entomological risk in epidemiological studies for prevention of dengue fever and routine surveillance of Aedes aegypti in this non-tropical location of the world. Due to its proximity to areas where dengue fever is endemic and with fluid contact with them (people and goods), Salto is a valuable case study for other areas in the world that could be or are being invaded by this vector and, a as consequence, could be at risk of suffering dengue fever.

\section{Methods}

\section{Study area, study design and sampling}

The location of this study includes the whole urban area of the city of Salto, a 123,000 inhabited town in North-Western Uruguay $\left(31^{\circ} 23^{\prime \prime} \mathrm{S}, 57^{\circ} 58^{\prime \prime} \mathrm{W}\right)$. Various sections or cells of Salto were delimited by overlaying a sampling grid with 200 cells on a geo-referenced digital map of this city, using ArcGIS 9.3. The cells were numbered and 20 cells were randomly selected using simple random numbers (Figure 1).

The area or cluster to be covered was identified by starting at the bottom left corner of each cell where 100 premises (houses) were visited by interviewers. In order to facilitate the work of the interviewers, each one was given a map and an aerial photo of their cluster. Due to the exclusion of commercial properties from the survey, we were not able to identify other mosquito sources in the city.

An entomological survey identifying larvae / pupae of Aedes aegypti was carried out in the selected premises in order to calculate indices of mosquito density. Informed consent was sought from all interviewees and anonymity was assured with respect to recorded and reproduced interview data. The clusters were then geo-referenced and the geographic and demographic characteristics were established. The entomological survey focused on identification and quantification of Aedes aegypti larvae and pupae (presence or absence of larvae, and pupae count per container) in all water-filled containers present in yards, patios and other areas surrounding the homes. Surveys were carried out in two stages: from November to December 2010 (spring in the Southern Hemisphere, low vector density due to low temperatures) and from April to May 2011 (autumn in the Southern Hemisphere, elevated vector densities due to higher temperatures). Although Uruguay does not have distinct dry and wet seasons but rather periods of rain spread out almost equally throughout the year, water deficit occurs during the summer despite high values of rainfall (very high temperatures and high solar radiation jointly bring about large values of water vapor atmospheric demand), the first survey-period coincided with a period of drought and the second with frequent rainfall (148 $\mathrm{mm}$ and $304 \mathrm{~mm}$, respectively, Official data form the National Weather Service, Uruguay). Field work was conducted by 14 people trained and supervised by the project team members and by officials of the dirección departamental de salud de salto (DDSS) of the MPH. The surveyors had experience with these types of surveys as they had previously carried out entomological surveys of Aedes aegypti for the MPH. 
Citation: Basso C,Garcia da Rosa E, Lairihoy R, Gonzalez C, Norbis W, et al. (2016) Epidemiologically Relevant Container Types, Indices of Abundance and Risk Conditions for Aedes aegypti in Salto (Uruguay), a City under Threat of Dengue Disease. J Infect Dis Pathol 1: 103.

Page 3 of 9

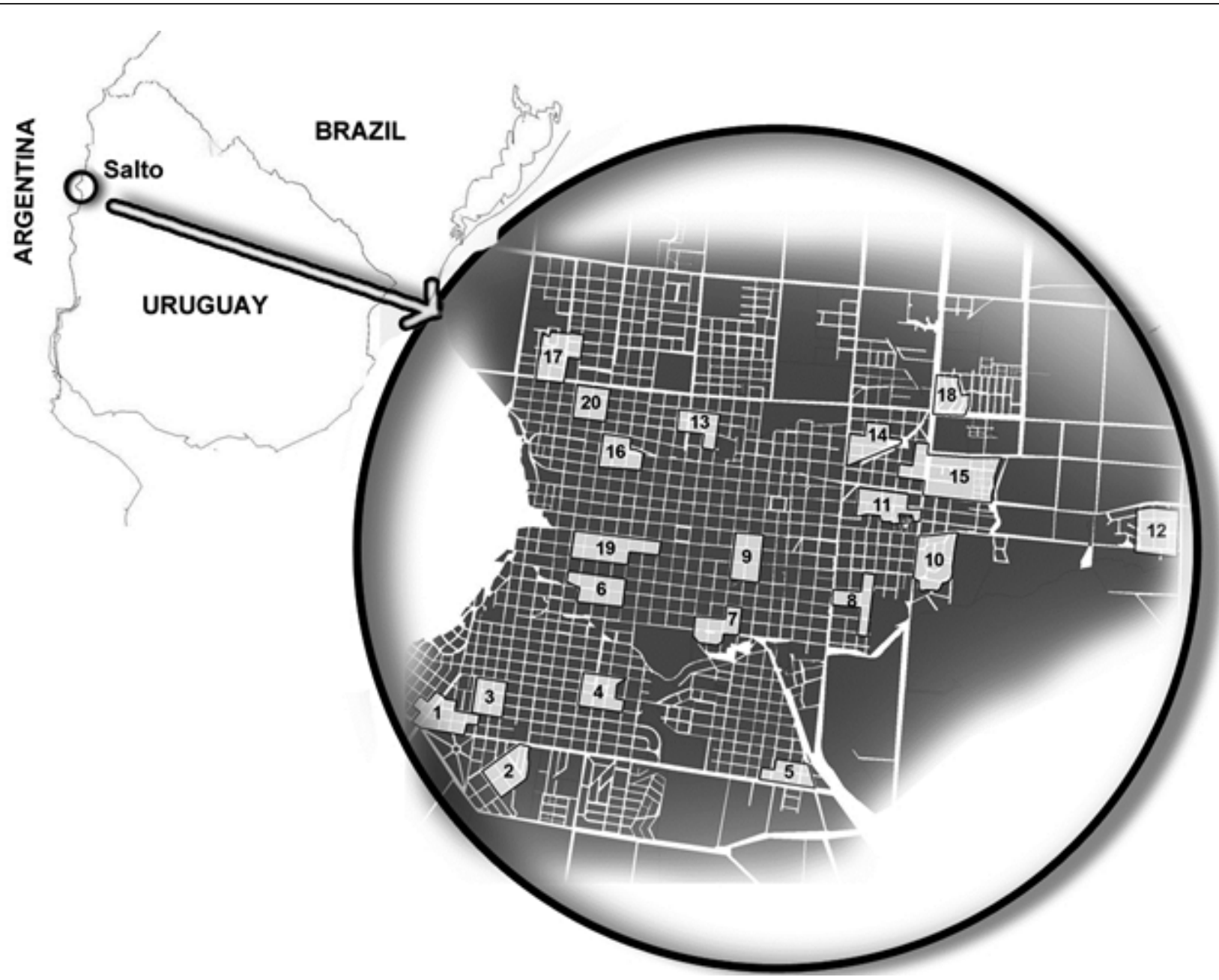

Figure 1: Map of the city of Salto (Uruguay) showing sampling sites.

The containers detected were counted and classified based on their size and use (in use =routinely used; not in use $=$ abandoned or stacked) in Uruguayan households: [1: Tanks (capacity $\geq 200$ liters, used to collect water), 2: Large standing cement wash tanks (capacity: 10-50 liters, in use), 3: Paint-can sized water containers (capacity: 5-10 liters, used for household chores), 4: Buckets (capacity: 5-20 liters, used as troughs), 5: Others (in use), 6: Paint-can sized water containers (capacity: 5-10 liters, not in use), 7: Flower vases (not in use), 8: Tires (not in use), 9: Bottles (capacity: 1-2 liters) and small miscellaneous containers (not in use), 10: Natural containers (not in use) and 11: Others (not in use)], source of water, volume, location, the presence of vegetation and the presence of a lid. Only wet containers were recorded.

All larvae and pupae found were stored in small vials with alcohol (identifying the container they came from) and transported to the laboratory of the DDSS-MPH, where the larvae and pupae were identified using the Darsie key [34] and counted. The corresponding Stegomyia indices (CI, HI, BI), PPI and PHI were calculated for clusters and for the overall study area.

\section{Spatial representation}

To represent the pattern of spatial distribution of events (PPI) based on the corresponding coordinates, we used data interpolation and data smoothing using the Gaussian kernel [35]. This method allows estimating the probability of the occurrence of an event in each cell of a regular grid, with each cell of this grid being the weighted average of all values for that site. These values are assigned using a probability distribution function- in this case Gaussian. The degree of smoothing is controlled by choosing a bandwidth which indicates the area to be considered in the calculation. This area should be related to the geographic scale of the hypothesis of interest or to prior knowledge about the problem under study [36]. In agreement with Souza-Santos and Carvalho [35] this analysis used a bandwidth of $300 \mathrm{~m}$ based on dispersion of the female Aedes aegypti when they are not able to find suitable containers for females oviposit [37].

Next, the urban and geographic characteristics of the sites located in the city of Salto, the environmental conditions of the homes, the areas around houses and open spaces and the characteristics of the population were described and analyzed. We used data from the Geographic Information System "Arc-View" detailing density and type of vegetation and construction, land size, sanitation systems, street and 
Citation: Basso C,Garcia da Rosa E, Lairihoy R, Gonzalez C, Norbis W, et al. (2016) Epidemiologically Relevant Container Types, Indices of Abundance and Risk Conditions for Aedes aegypti in Salto (Uruguay), a City under Threat of Dengue Disease. J Infect Dis Pathol 1: 103.

Page 4 of 9

sidewalk paving, storm sewer systems, topography, floodplains, access roads to the city, transport terminals and the socio-economic level of the population. This information was provided by the Municipality of Salto and was used in addition to our own calculations from cartography and photo interpretation of satellite photographs from Google Earth and photographs taken in the city.

\section{Statistical analysis}

A statistical analysis of the results from the first (November to midDecember 2010) and second (from April to mid-May 2011) entomology surveys results was carried out using a non-parametric Kruskall-Wallis analysis of variance. When significant differences were found, a Mann-Whitney test with Bonferroni corrections was performed. In all cases a significance level of $\mathrm{p}=0.05$ was used.

The pupal counts were used to calculate the PPI and PPH. We used a nonparametric (distribution-free) Spearman's rank correlation coefficient [38] to measure the strength of the association between two ranked variables with a monotonic relationship between them (in this case the two indices).

\section{Scientific team}

The study involved researchers from the University of the Republic of Uruguay and the Ministry of Public Health, part of a multidisciplinary team which used an ecosystem approach based on the principles of Ecohealth (this approach to health focuses on the interactions between the ecological and socio-economic dimensions of a given situation, and their influence on human health, as well as how people use or impact ecosystems, the implications for the quality of ecosystems, the provision of ecosystem service, and sustainability) [39] to prevent and control the proliferation of the dengue vector [40]. The results from this study will be integrated with the results from social research carried out by other members of the team, to formulate an eco-bio-social proposal to help prevent dengue fever in Salto-Uruguay.

\section{Results}

\section{Container Classification, Productivity and Aedes aegypti Indices}

The buckets were the most abundant containers in use in both the first and second sampling ( $45 \%$ and $52 \%$, respectively). Next in importance were the large standing cement wash tanks in use $(22 \%$ and $10 \%)$ and tanks in use (drums, barrels) (14\% and 12\%) in both the first and second sampling respectively.

The water containers not in use including the flower vases, tires, paint-can sized water containers, bottles and miscellaneous small containers, and other containers represent only a small percentage of the total number of containers $(6 \%$ and $13 \%$ in the first and second sampling respectively), among which the bottles and miscellaneous small containers stand out ( $4 \%$ in both periods). Of all the containers with water examined in both of periods (period $1=1,089$; period $2=934$ ), the containers which were not in use had the highest productivity of Aedes aegypti pupae of the total number of containers, they produced $46 \%$ of pupae collected. Considering those 'others containers not in use' ( $2 \%$ of total number of containers) produced $19 \%$ of pupae collected. Buckets represented the largest fraction of used containers ( $48 \%$ of that total), but they only produced $12 \%$ of the pupae collected. While tanks, which were less than one third of the number of buckets, produced $20 \%$ of pupae collected (Table 1 ).

The differences in productivity of pupae by container type were significant $\quad(\mathrm{p}<0.05) \quad$ (Kruskall-Wallis, Hc: 231.5, $\mathrm{p}=1.70 \mathrm{E}-03)$ According to the Mann-Whitney (MW) a posteriori test with Bonferroni's correction, there is a significant difference $(\mathrm{p}<0.05)$ between the flower vases (higher productivity of pupae by container type value) tanks (in use) ( $\mathrm{p}=1.51 \mathrm{E}-05)$, paint-can sized water containers (in use) $(\mathrm{p}=1.96 \mathrm{E}-06)$, others containers (in use) ( $\mathrm{p}=6.97 \mathrm{E}-10)$, buckets (in use) $(\mathrm{p}=3.10 \mathrm{E}-36)$, and large standing cement wash tanks (in use) (lower productivity of pupae by container type value) $(\mathrm{p}=1.44 \mathrm{E}-32)$. Also there is a significant difference $(\mathrm{p}<0.05)$ between the tanks in use regarding large standing cement wash tank $(\mathrm{p}=0.001325)$, buckets $(\mathrm{p}=1.03 \mathrm{E}-06)$ and others unused recipients $(\mathrm{p}=0.003748)$; between large standing cement wash tank regarding paint-can sized water containers $(p=2.40 \mathrm{E}-11)$, tires $(\mathrm{p}=8.00 \mathrm{E}-14)$, bottles and small miscellaneous containers $(\mathrm{p}=2.00 \mathrm{E}-09)$ and others unused recipients $(\mathrm{P}=1.14 \mathrm{E}-15)$; between paint-can sized water containers regarding tires $(\mathrm{p}=0.02592)$ and others unused recipients $(\mathrm{p}=0.004284)$; between buckets regarding paint-can sized water containers $(p=6.51 \mathrm{E}-15)$, tires $(\mathrm{p}=1.81 \mathrm{E}-19)$, bottles and small miscellaneous containers $(\mathrm{p}=3.52 \mathrm{E}-17)$ and others unused recipients $(\mathrm{p}=1.03 \mathrm{E}-27)$; and between others recipients in use regarding paintcan sized water containers $(\mathrm{p}=0.00455)$, tires $(\mathrm{p}=0.0004747)$, bottles and small miscellaneous containers $(\mathrm{p}=0.01362)$ and others unused recipients $(\mathrm{p}=4.16 \mathrm{E}-05)$ (Table 1$)$.

Significant differences $(\mathrm{p}<0.05) \quad$ (Kruskall-Wallis, Hc: 250.9, $\mathrm{p}=6.16 \mathrm{E}-13$ ) were found considering the origin of the water in the containers. According to the Mann-Whitney (MW) a posteriori test with Bonferroni's correction, there is a significant difference $(\mathrm{p}<0.05)$ between the drinking water supply network regarding rain water $(\mathrm{p}=5.42 \mathrm{E}-57)$ and water from two sources $(\mathrm{p}=5.47 \mathrm{E}-06)$. More than $80 \%$ of the water in the containers came from the drinking water supply network. However, $76 \%$ of pupae were found in containers with rain water, where productivity per container was significantly higher than that of the containers filled with water from a piped water supply. In the case of containers which received water from two sources, productivity was not significantly different from containers with rain water (Table 2).

The vast majority of containers were uncovered (80\%) and from these $78 \%$ of pupae were collected. Productivity in the containers was not significantly different when they were fully or partially covered or uncovered (Kruskall-Wallis, Hc: 2,386, $\mathrm{p}=0.873$ ). Even when more than $78 \%$ of the containers were not placed under vegetation (neither completely nor partially), only $68 \%$ of the total number of pupae collected were obtained from those. Despite some variation in productivity between containers could be established, those productivity differences among containers were not statistically significant (Kruskall-Wallis, Hc: 2,386, p=0.873).

In the containers which had been in use within the previous 7 days for both sampling periods (representing $84 \%$ of the total number of containers) only $16 \%$ of the pupae were collected. The water containers which had not been used during this period had significantly more pupae production $(\mathrm{p}<0.01)$ (Mann-Whitney test, $\mathrm{T}$ : $\mathrm{Ub}$ : $1.91 \mathrm{E}+05$, $\mathrm{p}=3.34 \mathrm{E}-60)$. 
Citation: Basso C,Garcia da Rosa E, Lairihoy R, Gonzalez C, Norbis W, et al. (2016) Epidemiologically Relevant Container Types, Indices of Abundance and Risk Conditions for Aedes aegypti in Salto (Uruguay), a City under Threat of Dengue Disease. J Infect Dis Pathol1: 103.

Page 5 of 9

\begin{tabular}{|c|c|c|c|c|c|}
\hline Type of Container & $\begin{array}{l}\text { Number of } \\
\text { containers }\end{array}$ & $\begin{array}{l}\text { Total number of } \\
\text { pupae }\end{array}$ & $\%$ of total pupae & Pupae/cont. (average)* & Standard Error \\
\hline Flower vases & 4 & 22 & 4.98 & $5.50 \mathrm{a}$ & 3.43 \\
\hline Others (not in use) & 47 & 85 & 19.23 & $1.81 \mathrm{a}$ & 1.03 \\
\hline Tires & 23 & 30 & 6.79 & $1.30 \mathrm{ac}$ & 0.6 \\
\hline $\begin{array}{l}\text { Paint-can sized water containers (not in } \\
\text { use) }\end{array}$ & 22 & 28 & 6.33 & 1.27 acd & 0.63 \\
\hline Others (in use) & 145 & 63 & 14.25 & $0.43 \mathrm{bf}$ & 0.41 \\
\hline $\begin{array}{l}\text { Bottles and small miscellaneous } \\
\text { containers (not in use) }\end{array}$ & 92 & 38 & 8.6 & $0.41 \mathrm{acd}$ & 0.12 \\
\hline Tanks (in use) & 265 & 88 & 19.91 & $0.33 \mathrm{bcd}$ & 0.1 \\
\hline Paint-can sized water containers (in use) & 127 & 31 & 7.01 & $0.24 \mathrm{bdf}$ & 0.12 \\
\hline Buckets (in use) & 968 & 55 & 12.44 & 0.06 ef & 0.03 \\
\hline $\begin{array}{l}\text { Large standing cement wash tanks (in } \\
\text { use) }\end{array}$ & 330 & 2 & 0.45 & 0.01 ef & 0 \\
\hline Natural containers (not in use) & 0 & 0 & 0 & 0 & 0 \\
\hline
\end{tabular}

Table 1: Number of containers with water by type and number of pupae collected in peridomestic areas of household: combined results from Surveys 1 and 2. Means followed vertically by the same letter are not significantly different $(\mathrm{p}<0.05)$ in a Mann-Whitney test with Bonferroni corrections.

\begin{tabular}{|c|c|c|c|c|c|c|}
\hline Source of water & Number of containers & Number of pupae & $\begin{array}{c}\text { Number of pupae / } \\
\text { container (average) }\end{array}$ & Standard Error & $\begin{array}{c}\text { \% of total container } \\
\text { \% of total } \\
\text { pupae }\end{array}$ & \begin{tabular}{c} 
(aval \\
\hline Drinking water
\end{tabular} \\
\hline Rain water & 1620 & 45 & 0.02778 & 0.0125 & 10.2 \\
\hline Both & 341 & 338 & 0.9912 & 0.2458 & 16.9 & 76.5 \\
\hline
\end{tabular}

Table 2: Containers and pupae produced according to source of water. It was used the Mann-Whitney a posteriori test with Bonferroni's correction between the drinking water supply network regarding rain water and water from two sources.

Even though all of the Aedes aegypti indices increased in the second survey (Table 3, S 3), neither the PPI nor PHI differed significantly between the first and second survey, although the Stegomyia indices did differ significantly between the two periods (Table 4). The PPI values varied dramatically among the clusters, for both the first and the second survey (Figure 2). In the first survey, both the HI and BI, and the PPI and PHI, were significantly correlated. In the second survey all indices were correlated (Table 5).

\begin{tabular}{|l|l|l|l|l|l|}
\hline Date & HI & CI & BI & PPI & PHI \\
\hline Survey 1 & 0.4 & 0.7 & 0.4 & 0.01 & 0.2 \\
\hline Survey 2 & 4.4 & 12.5 & 6.8 & 0.06 & 1.7 \\
\hline
\end{tabular}

Table 3: Estimated values of the Container Index (CI), House Index (HI), Breteau Index (BI), number of Pupae per person Index (PPI) and number of Pupae per hectare Index (PHI) for the two sampling dates in Salto (Uruguay). Survey $1=$ November-December 2010; Survey 2=April-May 2011 .

\begin{tabular}{|c|c|c|c|c|c|}
\hline & HI & Cl & BI & PPI & PHI \\
\hline & S1-S2 & S1-S2 & S1-S2 & S1-S2 & S1-S2 \\
\hline T=Ub: & 14 & 6 & 13 & 42 & 41 \\
\hline P(same): & 0.019 & 0.0036 & 0.0156 & 0.7221 & 0.6695 \\
\hline Monte Carlo p: & 0.0157 & 0.0011 & 0.0117 & 0.7385 & 0.6809 \\
\hline Exact p: & 0.0148 & 0.0014 & 0.0112 & 0.7304 & 0.679 \\
\hline
\end{tabular}

Table 4: Analysis of different indicators between the two surveys using the non-parametric Mann-Whitney test. S1: survey 1, S2: survey 2. $\mathrm{T}=\mathrm{Ub}$ : value of the statistic. Bold values indicate significant differences between surveys $(\mathrm{p}<0.05)$.

\section{Urban characterization of clusters with highest PPI}

Of all the clusters that were studied, clusters 1 (PPI=0.19), 15 $(\mathrm{PPI}=0.35)$ and $16(\mathrm{PPI}=0.24)$ showed greater $\mathrm{PPI}$ values in the second survey. Clusters 1 and 15 are located on the edge of the urban area, along bypass and access roads (by which Aedes aegypti can be 
Citation: Basso C,Garcia da Rosa E, Lairihoy R, Gonzalez C, Norbis W, et al. (2016) Epidemiologically Relevant Container Types, Indices of Abundance and Risk Conditions for Aedes aegypti in Salto (Uruguay), a City under Threat of Dengue Disease. J Infect Dis Pathol 1 : 103.

Page 6 of 9

imported from neighboring areas), very close to the surrounding countryside. Properties may be adjacent to large open spaces with little control and areas with abundant vegetation. Cluster 1 has no sewage system, streets and sidewalks are not paved, and many ditches are present. There is a low density of individual housing and abundant vegetation in all areas around and in between houses. Cluster 15 also has low housing density and is bordered by an area with no houses which slopes down to a stream. It is characterized by dirt roads, abundant vegetation, factories and warehouses. In the immediate surrounding area there is a football stadium, a tire shop, an area of shacks, and full-time elementary and high schools. In the town outskirts there are plenty of open spaces with vegetation, where large housing properties or properties used for other purposes can also be found. All those buildings are difficult to maintain.

\begin{tabular}{|c|c|c|c|c|c|c|}
\hline & & HI & Cl & BI & PPI & PHI \\
\hline \multirow{4}{*}{$\begin{array}{c}\text { First } \\
\text { Survey }\end{array}$} & $\mathrm{HI}$ & 0 & 0.233 & 0.017 & 0.233 & 0.683 \\
\cline { 2 - 7 } & $\mathrm{Cl}$ & 0.61 & 0 & 0.233 & 0.683 & 0.783 \\
\cline { 2 - 7 } & $\mathrm{BI}$ & 1 & 0.59 & 0 & 0.233 & 0.683 \\
\cline { 2 - 7 } & $\mathrm{PPI}$ & -0.62 & -0.23 & -0.6 & 0 & 0.45 \\
\cline { 2 - 7 } & $\mathrm{PHI}$ & 0.22 & -0.13 & 0.22 & -0.4 & 0 \\
\hline \multirow{4}{*}{$\begin{array}{c}\text { Second } \\
\text { Survey }\end{array}$} & $\mathrm{HI}$ & 0 & 0.0000182 & 0.000000263 & 0.014 & 0.01 \\
\cline { 2 - 7 } & $\mathrm{CI}$ & 0.82 & 0 & 0.00000197 & 0.076 & 0.016 \\
\cline { 2 - 7 } & $\mathrm{BI}$ & 0.89 & 0.86 & 0 & 0.026 & 0.003 \\
\cline { 2 - 7 } & $\mathrm{PPI}$ & 0.3 & 0.42 & 0.51 & 0 & 0 \\
\cline { 2 - 7 } & $\mathrm{PHI}$ & 0.57 & 0.54 & 0.65 & 0.86 & 0 \\
\hline
\end{tabular}

Table 5: Non-parametric Spearman's correlation analysis between HI, $\mathrm{CI}, \mathrm{BI}, \mathrm{PPI}$ and PHI. In Bold, significant probability values $(\mathrm{p}<0.05)$. In italics, the corresponding correlation coefficient values.

Cluster 16 lies fully within the urban area, but is located on lower ground, near a stream, with dense native forest and large, uncared-for public spaces. The area has low density housing. The houses are old and have yards which are at risk of flooding. Humid areas encourage vegetation growth and make maintenance difficult for the residents.

Environmental conditions and the aforementioned problem of space maintenance in clusters 1,15 and 16 has had probably an influence on the fact that, even when only $18 \%$ of the containers with unused water of the 20 clusters were reported in those three clusters, such containers produced $42 \%$ of the total pupae found in all the clusters.

\section{Discussion}

Historically, entomologic surveillance for dengue was dominated by the use of larval surveys, mostly because Aedes aegypti control grew out of an elimination paradigm that promoted complete, thorough and repeated coverage of infested areas [41]. Since the elimination of Aedes aegypti is an unattainable goal, today most dengue control efforts are based on suppression of Aedes aegypti and not on elimination [42,43]. Those efforts are better accomplished if a suitable level of reduction of mosquitoes is known. And also knowing the methodologies to achieve that level, monitor it and select correctly the most productive containers regarding optimal labor efficiency, cost reduction and maximum elimination of adults [44,45]. Entomological surveillance was/is always based on larval indices showing basically the presence/ absence of the vector. Pupal indices are mainly for identifying the most productive container types and to get a clue for vector densities. Ideally both adult vectors should be killed through ITN (insecticide-treated nets) curtains or water container covers and at the same time the most productive container types should be targeted. One research programme in Latin America [46] (and previously in Asia [47]) has shown that you can achieve a significant impact on vector densities by implementing one or the other strategy but best both together. When you have low vector densities and no virus transmission (like in Uruguay), it makes sense to keep the vectors down by killing the immature stages particularly in the productive container types.

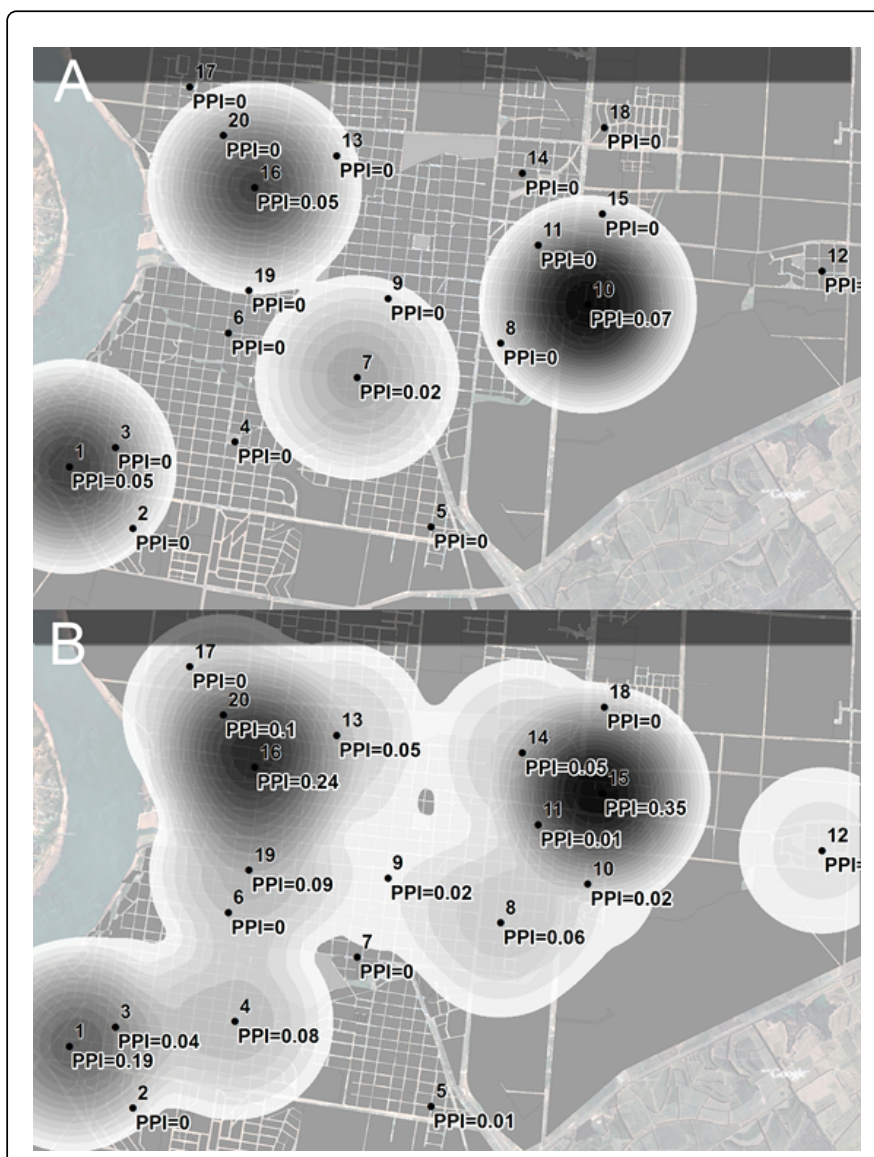

Figure 2: PPI representation in the city of Salto (Kernel method). A: survey 1 (from November to mid December 2010); B: survey 2 (from April to mid May 2011). It was used data interpolation and data smoothing using the Gaussian kernel [35].

In contrast to the results obtained in a previous study in Salto [20], the current study was able to detect epidemiologically relevant containers (type and use). In the present study the number of sampled dwellings was 6.4 times larger than in the previous one by Basso, et al. [20]. An increase that was probably responsible for finding such significant differences. In this regard, in such regions of the world in which Aedes aegypti is present, albeit in low numbers, studies should cover almost the whole area under survey, in order to obtain consistent results. 
Citation: Basso C,Garcia da Rosa E, Lairihoy R, Gonzalez C, Norbis W, et al. (2016) Epidemiologically Relevant Container Types, Indices of Abundance and Risk Conditions for Aedes aegypti in Salto (Uruguay), a City under Threat of Dengue Disease. J Infect Dis Pathol1: 103.

Page 7 of 9

In fact, although only a small number of the total containers surveyed were not in use (9\%), they produced $46 \%$ of pupae collected. Additionally, while the tanks only accounted for $13 \%$ of surveyed containers they produced $20 \%$ of total pupae collected. 'Other unused containers' produced a large share of the pupae collected. In spite that they amounted only to $2 \%$ of the total number of containers, $19 \%$ of the pupae were collected there.

Pupal productivity surveys are a useful tool for prioritizing vectorcontrol interventions as has been suggested by other authors [26-33,48-50]. Infestation of a household is mostly function of container management practices by residents of the property and the ecology of Aedes aegypti [41]. Since it has been shown that productivity increases after a period of 7 days of non-usage a weekly revision and disposal of unused containers would be advisable.

While the PPI, PHI and Stegomyia indices for the different clusters were correlated in the second sampling, the Stegomyia indices increased significantly between the first and second sampling, but not the PPI and PHI. This result differs from that reported by Bisset, et al. [51] who indicated that although each of the three Stegomyia indices was closely correlated with the other two ( $<<0.05$ for each), no statistically significant correlations were observed between any of the pupal indices calculated (the numbers of pupae per person, per container inspected, and per hectare) and any of the Stegomyia indices. The highest PPI values which were obtained in the second survey (PPI $=0.06$ ), would not be sufficient indication of possible dengue outbreaks according to the computer models by Focks, et al. [52] (PPI=7.13 with a temperature of $22^{\circ} \mathrm{C}$ ), considering that dengue herd immunity in the urban population of Salto can be considered to be close to zero. This is due to the fact that there has been no reported virus transmission in recent years and that monthly average temperature during the second survey was $18^{\circ} \mathrm{C}$. This indicates that the increase observed in the number of pupae collected in the second sample does not necessarily mean an increased risk of dengue fever transmission. It should be taken into account, however, that the Focks, et al. models [52] establishing PPI thresholds for epidemic transmission-have yet to be validated.

Water containers shaded by vegetation showed no significant increase in vector productivity compared to non-shaded containers, a difference with the findings of other authors, who found a positive relationship [29,53]. However, the fact that in our study $42 \%$ of the total pupae found in all the clusters were found in only three clusters with plenty of carelessly maintained vegetation under which water containers can be kept, gives a guide to be kept into account at the moment of defining high risk conditions regarding a higher incidence of Aedes aegypti Other conditions beneficial to Aedes aegypti, as mentioned elsewhere [54-56], were present at some of these areas, such as neighborhoods along or contiguous with the main roads and points of access (leading to an influx of people and goods), unplanned urbanization, and warehouses also create conditions for risk areas. Such relationships should be the subject of future studies in Uruguay and used for selecting the disposal of those containers that are exposed to environmental conditions conducive to greater Aedes aegypti productivity.

Given that the cluster with the highest PPI value also had the highest concentration of unused containers (bottles, tires, abandoned small containers) suggest that the task of preventing and reducing Aedes aegypti breeding areas should focus on reducing these containers, and spreading the word about the risk of leaving containers with water standing for more than 7 consecutive days. Considering their high productivity and reduced numbers in relation to other containers, proper sealing, removal or replacement of tanks must be also encouraged. Public institutions and local population should maximize efforts aiming to reducing the sources of Aedes aegypti (specially the most productive ones) and should maintain urban areas in such conditions that the development of Aedes aegypti can be reduced and dengue outbreaks prevented. Taking into account that dengue is nowadays not even present in Salto and that the attention of the population is focused on other health problems; educational campaigns and right messages should help bring behavioral changes to the population. Changes should aim at improving environmental management practices that help prevent the disease. Salto can be considered a 'case study' of new areas that Aedes aegypti will reach if, as is expected in a climate change context, the mosquito's distribution extends.

\section{Acknowledgment}

We thank the Ministry of Public Health authorities and the field team for conducting the surveys; the Municipality of Salto; all the people who allowed us onto their property for collecting the data; and Rodrigo Fernandez for creating the figures. This study was supported by a grant from the Special Programme for research and training in tropical diseases (TDR) at the World Health Organization, in collaboration with its regional office for the Americas (PAHO) and in partnership with the Ecosystem and Human Health Program of the international development research centre (IDRC) of Canada to develop a research program under the title "Towards Improved Dengue and Chagas Disease Control through Innovative Ecosystem Management and Community-Directed Interventions: An Eco-BioSocial Research Programme on Dengue and Chagas Disease in Latin America and the Caribbean" (Project Number 104951-001). There are no relationships or support which might be perceived as constituting a conflict of interest.

\section{References}

1. Guzman MG, Halstead SB, Artsob H, Buchy P, Farrar J, et al. (2010) Dengue: a continuing global threat. Nat Rev Microbiol 8: S7-16.

2. Simmons CP, Farrar JJ, Nguyen vV, Wills B (2012) Dengue. N Engl J Med 366: 1423-1432.

3. Bhatt S, Gething PW, Brady OJ, Messina JP, Farlow AW, et al. (2013) The global distribution and burden of dengue. Nature 496: 504-507.

4. World Health Organization (2012) Global strategy for dengue prevention and control 2012-2020.

5. Brady OJ, Gething PW, Bhatt S, Messina JP, Brownstein JS, et al. (2012) Refining the global spatial limits of dengue virus transmission by evidence-based consensus. PLoS Negl Trop Dis 6: e1760.

6. Vezzani D, Carbajo AE (2008) Aedes aegypti, Aedes albopictus, and dengue in Argentina: current knowledge and future directions. Mem Inst Oswaldo Cruz 103: 66-74.

7. Wilder-Smith A, Schwartz E (2005) Dengue in travelers. N Engl J Med 353: 924-932.

8. Earnest A, Tan SB, Wilder-Smith A (2011) Meteorological factors and El Nino Southern Oscillation are independently associated with dengue infections. Epidemiol Infect: 1-8.

9. Favier C, Degallier N, Vilarinhos Pde T, de Carvalho Mdo S, Yoshizawa MA, et al. (2006) Effects of climate and different management strategies on Aedes aegypti breeding sites: a longitudinal survey in Brasília (DF, Brazil). Trop Med Int Health 11: 1104-1118.

10. Hii YL, Rocklöv J, Ng N, Tang CS, Pang FY, et al. (2009) Climate variability and increase in intensity and magnitude of dengue incidence in Singapore. Glob Health Action 2. 
Citation: Basso C,Garcia da Rosa E, Lairihoy R, Gonzalez C, Norbis W, et al. (2016) Epidemiologically Relevant Container Types, Indices of Abundance and Risk Conditions for Aedes aegypti in Salto (Uruguay), a City under Threat of Dengue Disease. J Infect Dis Pathol 1: 103.

Page 8 of 9

11. Schmidt-Chanasit J, Haditsch M, Schoneberg I, Gunther S, Stark K, et al. (2010) Dengue virus infection in a traveller returning from Croatia to Germany. Euro Surveill 15.

12. La RG, Souares Y, Armengaud A, Peloux-Petiot F, Delaunay P, et al. (2010) First two autochthonous dengue virus infections in metropolitan France, September 2010. Euro Surveill 15: 19676.

13. Jaenisch T, IDAMS, Sakuntabhai A, DENFREE, Wilder-Smith A, et al. (2013) Dengue Research Funded by the European Commission-Scientific Strategies of Three European Dengue Research Consortia. PLoS Negl Trop Dis 7: e2320.

14. Grech M, Visintin A, Laurito M, Estallo E, Lorenzo P, et al. (2012) New records of mosquito species (Diptera: Culicidae) from Neuquén and La Rioja provinces, Argentina. Rev Saude Publica 46: 387-389.

15. Díaz-Nieto LM, Maciá A, Perotti MA, Berón CM (2013) Geographical limits of the Southeastern distribution of Aedes aegypti (Diptera, Culicidae) in Argentina. PLoS Negl Trop Dis 7: e1963.

16. Salvatella R (1997) Aedes aegypti (Diptera, Culicidae). Notificación de su presencia en Uruguay. Rev Med Uruguay 13: 118-121.

17. García da Rosa E, Lairihoy R, Leivas JC, González W, Paulino D (2003) Monitoreo de Aedes aegypti mediante el uso de ovitrampas. Entomol Vect 10: 451-456.

18. Ministerio de Salud Pública (2011).

19. San Martín JL, Brathwaite O, Zambrano B, Solórzano JO, Bouckenooghe A, et al. (2010) The epidemiology of dengue in the americas over the last three decades: a worrisome reality. Am J Trop Med Hyg 82: 128-135.

20. Basso C, Caffera RM, García da Rosa E, Lairihoy R, González C, et al. (2012) Mosquito-producing containers, spatial distribution and relationship between Aedes aegypti population indices on the southern boundary of its distribution in South America (Salto-Uruguay). Am J Trop Med Hyg 87: 1083-1088.

21. Christophers R (1960) Aedes aegypti (L.). The Yellow Fever Mosquito Cambridge University Press, Cambridge.

22. Focks DA, Haile DG, Daniels E, Mount GA (1993) Dynamic life table model for Aedes aegypti (Diptera: Culicidae): analysis of the literature and model development. J Med Entomol 30: 1003-1017.

23. Focks DA, Haile DG, Daniels E, Mount GA (1993) Dynamic life table model for Aedes aegypti (diptera: Culicidae): simulation results and validation. J Med Entomol 30: 1018-1028.

24. Caffera RM (2010) Influencias atmosféricas y climáticas en la transmisión del dengue. In: Basso C, ed. Abordaje ecosistémico para prevenir y controlar al vector del dengue en Uruguay. Universidad de la República, Montevideo. pp. 149-168.

25. Focks DA (2003) A Review of Entomological Sampling Methods and Indicators for Dengue Vectors. Special Program for Research and Training in Tropical Diseases (TDR), UNICEF, UNDP, World Bank, World Health Organization.

26. Chadee DD (2004) Key premises, a guide to Aedes aegypti (Diptera: Culicidae) surveillance and control. Bull Entomol Res 94: 201-207.

27. Focks DA, Chadee DD (1997) Pupal survey: an epidemiologically significant surveillance method for Aedes aegypti: an example using data from Trinidad. Am J Trop Med Hyg 56: 159-167.

28. Arredondo-Jiménez JI, Valdez-Delgado KM (2006) Aedes aegypti pupal/ demographic surveys in southern Mexico: consistency and practicality. Ann Trop Med Parasitol 100 Suppl 1: S17-17S32.

29. Barrera R, Amador M, Clark GG (2006) Use of the pupal survey technique for measuring Aedes aegypti (Diptera: Culicidae) productivity in Puerto Rico. Am J Trop Med Hyg 74: 290-302.

30. Focks DA, Alexander N (2006) Multicounty study of Aedes aegypti pupal productivity survey methodology: findings and recommendations. World Health Organization/Special Programme for Research and Training in Tropical Diseases.

31. Lenhart AE, Castillo CE, Oviedo M, Villegas E (2006) Use of the pupal/ demographic-survey technique to identify the epidemiologically important types of containers producing Aedes aegypti (L.) in a dengueendemic area of Venezuela. Ann Trop Med Parasitol 100: 53-59.
32. Chadee DD, Huntley S, Focks DA, Chen AA (2009) Aedes aegypti in Jamaica, West Indies: container productivity profiles to inform control strategies. Trop Med Int Health 14: 220-227.

33. Midega JT, Nzovu J, Kahindi S, Sang RC, Mbogo C (2006) Application of the pupal/demographic-survey methodology to identify the key container habitats of Aedes aegypti (L.) in Malindi district, Kenya. Ann Trop Med Parasitol 100 Suppl 1: S61-61S72.

34. Darsie RF Jr (1985) Mosquitoes of Argentina. Part I. Keys for identification of adult females and fourth stage larvae in English and Spanish (Diptera: Culicidae). Mosq Syst 17: 153-253.

35. Souza-Santos R, Carvalho MS (2000) [Spatial analysis of Aedes aegypti larval distribution in the Ilha do Governador neighborhood of Rio de Janeiro, Brazil]. Cad Saude Publica 16: 31-42.

36. Santos SM, Barcellos C, Carvalho MS, Flôres R (2001) [Spatial clusters detection of violent deaths in Porto Alegre, Rio Grande do Sul, Brazil, 1996]. Cad Saude Publica 17: 1141-1151.

37. Trpis M, Häusermann W, Craig Jr GB (1995) Estimates of population size, dispersal, and longevity of domestic Aedes aegypti (Diptera: Culicidae) by mark-release-recapture in the Village of Shauri Moyo in Eastern Kenya. J Med Entomol 32: 27-33.

38. Lehmann EL, D'Abrera HJM (1998) Nonparametrics: statistical methods based on ranks. Prentice-Hall, Englewood Cliffs.

39. Charron DF (2012) Ecohealth research in practice. Innovative applications of an ecosystem approach to health. Springer-IDRC, Ottawa.

40. Basso C (2010) Abordaje ecosistémico para prevenir y controlar al vector del dengue en Uruguay. Montevideo: Universidad de la República.

41. Getis A, Morrison AC, Gray K, Scott TW (2003) Characteristics of the spatial pattern of the dengue vector, Aedes aegypti, in Iquitos, Peru. Am J Trop Med Hyg 69: 494-505.

42. Nathan MB, Knudsen AB (1991) Aedes aegypti infestation characteristics in several Caribbean countries and implications for integrated community-based control. J Am Mosq Control Assoc 7: 400-404.

43. Anon (1994) Dengue and Dengue Hemorrhagic Fever in the Americas: Guidelines for Prevention and Control. Sci. Pub. No: 548.

44. Focks DA, Brenner RJ, Chadee DD, Trosper JH (1998) The use of spatial analysis in the control and risk assessment of vector-borne diseases. Am Entomologist 45: 173-183.

45. Focks DA, Brenner RA, Daniels E, Hayes J (2000) Transmission thresholds for dengue in terms of Aedes aegypti pupae per person with discussion of their utility in source reduction efforts. Am J Trop Med Hyg 62: 11-18.

46. Sommerfeld J, Kroeger A (2015) Innovative community-based vector control interventions for improved dengue and Chagas disease prevention in Latin America: introduction to the special issue. Trans $\mathrm{R}$ Soc Trop Med Hyg 109: 85-88.

47. Sommerfeld J, Kroeger A (2012) Eco-bio-social research on dengue in Asia: a multicountry study on ecosystem and community-based approaches for the control of dengue vectors in urban and peri-urban Asia. Pathog Glob Health 106: 428-435.

48. Tun-Lin W, Kay BH, Barnes A (1995) Understanding productivity, a key to Aedes aegypti surveillance. Am J Trop Med Hyg 53: 595-601.

49. Morrison AC, Gray K, Getis A, Astete H, Sihuincha M, et al. (2004) Temporal and geographic patterns of Aedes aegypti (Diptera: Culicidae) production in Iquitos, Peru. J Med Entomol 41: 1123-1142.

50. Tun-Lin W, Lenhart A, Nam VS, Rebollar-Téllez E, Morrison AC, et al. (2009) Reducing costs and operational constraints of dengue vector control by targeting productive breeding places: a multi-country noninferiority cluster randomized trial. Trop Med Int Health 14: 1143-1153.

51. Bisset JA, Marquetti MC, Suárez S, Rodríguez MM, Padmanabha $H$ (2006) Application of the pupal/demographic-survey methodology in an area of Havana, Cuba, with low densities of Aedes aegypti (L.). Ann Trop Med Parasitol 100 Suppl 1: S45-45S51.

52. Focks DA, Brenner RJ, Hayes J, Daniels E (2000) Transmission thresholds for dengue in terms of Aedes aegypti pupae per person with discussion of their utility in source reduction efforts. Am J Trop Med Hyg 62: 11-18. 
Citation: Basso C,Garcia da Rosa E, Lairihoy R, Gonzalez C, Norbis W, et al. (2016) Epidemiologically Relevant Container Types, Indices of Abundance and Risk Conditions for Aedes aegypti in Salto (Uruguay), a City under Threat of Dengue Disease. J Infect Dis Pathol 1:

103.

Page 9 of 9

53. Barrera R, Amador M, Clark GG (2006) Ecological factors influencing Aedes aegypti (Diptera: Culicidae) productivity in artificial containers in Salinas, Puerto Rico. J Med Entomol 43: 484-492.

54. Tauil PL (2001) [Urbanization and dengue ecology]. Cad Saude Publica 17 Suppl: 99-102.

55. Guzmán MG, García G, Kourí G (2006) [Dengue and dengue hemorrhagic fever: research priorities]. Rev Panam Salud Publica 19: 204-215.
56. Guagliardo SA, Barboza JL, Morrison AC, Astete H, Vazquez-Prokopec G, et al. (2014) Patterns of geographic expansion of Aedes aegypti in the Peruvian Amazon. PLoS Negl Trop Dis 8: e3033. 